\title{
Transient global amnesia after pain interventions such as nerve block and intramuscular stimulation: a case report
}

\author{
Yongjae Han, Yongwon Cho \\ Department of Anesthesiology and Pain Medicine, Inje University College of Medicine, Busan, Korea
}

Received July 1, 2021

Revised July 23, 2021

Accepted August 10, 2021

Corresponding author

Yongjae Han

Department of Anesthesiology and

Pain Medicine, Busan Paik Hospital,

Inje University College of Medicine,

75 Bokji-ro, Jin-gu, Busan 47392,

Korea

Tel: +82-51-890-4216

Fax: +82-51-898-4216

E-mail: liman1004@gmail.com

ORCID:

https://orcid.org/0000-0001-7321-1376

\begin{abstract}
Transient global amnesia (TGA) is characterized by a sudden episode of memory loss that usually lasts for minutes to several hours but never longer than 24 hours. TGA is triggered by events such as Valsalva maneuver, acute emotional stress, sexual intercourse, or pain. Since case reports of TGA occurring after pain interventions are extremely rare, it may be difficult for the physician to respond appropriately. Although TGA is self-limiting, it is important for the physicians to be aware of this unique syndrome and to distinguish it from other neurological complications or local anesthetic toxicity. We report a case of a 57-year-old female patient who experienced TGA after pain interventions such as nerve block and intramuscular stimulation at a pain clinic. The symptoms disappeared within 1 hour without neurological sequelae.
\end{abstract}

Keywords: Amnesia; Transient global; Pain clinics; Memory disorders

\section{INTRODUCTION}

Since Fisher and Adams [1] first analyzed, reported, and named cases related to transient global amnesia (TGA), many studies have been reported. Nonetheless, the exact pathogenesis of TGA is unclear. TGA is a disease of unknown etiology, characterized by sudden form of anterograde and retrograde amnesia, with complete recovery within 24 hours and without any local neurological symptoms or signs [2,3]. Because case reports of TGA after pain intervention are extremely rare, it can be difficult for doctors to respond appropriately when experiencing these cases. Currently, no laboratory investigations are available to establish the diagnosis of TGA. Thus, the diagnosis relies on a detailed clinical history, cognitive evaluation, and physical examination [3]. The case report and review of TGA occurring after pain interventions are presented here, along with the typical clinical symptoms and diagnostic criteria. The differential diagnosis and treatment directions are discussed. This study was approved by the Institutional Review Board (IRB) of Inje University Paik Hospital (IRB number: 2021-07016). 


\section{CASE REPORT}

A 57-year-old female patient with a weight of $51 \mathrm{~kg}$ and a height of $153 \mathrm{~cm}$ complained of heavy pain in the right shoulder, neck, and occipital region. The patient's treatment history includes pain interventions at the pain clinic for neck and shoulder pain following a traffic accident three years ago. She had not been diagnosed with any other neurological complications or psychiatric complications such as posttraumatic stress disorder (PTSD). The chief complaint of the patient was restricted elevation of right upper limb due to pain that started several days before the hospital visit. During the physical examination conducted at the time of visit, there was tenderness in the right occipital region, right hind neck, and right shoulder, and the trigger point was palpated. Right suprascapular nerve block and right axillary nerve block were performed under ultrasound guidance in prone position with a pillow below the abdomen followed by intramuscular stimulation (IMS) of the right infraspinatus, deltoid, and triceps. During the IMS procedure, muscle twitching occurred several times. She complained of extreme pain during the overall procedure, and was sobbing and crying towards the end of the procedure.

The procedure lasted about 30 minutes, and the patient remained lying in a supine position on the bed for recovery and stability after completion. After approximately $10 \mathrm{~min}-$ utes, the patient woke up in confusion and began to repeat similar questions such as "Where am I?" and "How did I get here?" The vital signs were immediately measured and her blood pressure was 110/70 mmHg, heart rate 97 per minute, and oxygen saturation 98\%, which are normal values. Additional physical examination was conducted to identify any movement disorder or paresthesia, but no specific findings were observed. Several questions were then asked of the patient to determine the extent and characteristics of amnesia.
The patient had memories of personal identification information such as her name and family relations, but did not have a situational memory, such as time and place, which made her anxious.

She was asked to contact her family, but she said that her family is busy and unavailable, and then she repeated the questions: "How did I get here?" and "Are these clothes next to me mine?" When we answered her repeated questions, she appeared to understand the situation briefly, but within minutes, she repeated the same question again. After about an hour, the patient suddenly stated, "Ah! I was here for treatment! I remember now." She showed partial recovery of her memory. She remembered that she felt severe pain while undergoing the procedure, but could not recall the subsequent events. Further neurological evaluation including brain $\mathrm{CT}$ and other tests were recommended, but she refused and was unable to perform additional tests. She was advised to visit the hospital in case of repeated neurological symptoms or abnormalities, and then she returned home. She returned for outpatient treatment two weeks later, and stated that she did not develop any neurological symptoms after that day, but still could not remember what happened during the transient amnesia that occurred two weeks ago.

\section{DISCUSSION}

TGA is a syndrome with a dramatic recovery without leaving any neurological sequelae, but only partial memory loss, while maintaining normal neurological function although the exact pathogenesis is unclear [1-5]. Tension-related factors were found in many of the reported cases, and despite differences in temporal variation in memory, full recovery occurs within 24 hours [2,3]. Clinically, the incidence rate is 3.4 to 10.4 per 100,000 people, and if the range is narrowed down to ages 50 or older, the incidence rate is increased to

Table 1. Diagnostic criteria for transient global amnesia

Attack must be witnessed and information available from a capable observer who was present for most of the attack

Clear-cut anterograde amnesia during the attack

Cognitive impairment limited to amnesia, without clouding of consciousness or loss of personal identity

No accompanying focal neurologic symptoms during the attack and no significant neurologic signs afterward

Absence of epileptic features

Resolution of the attack within $24 \mathrm{~h}$

Patients with recent head injury or active epilepsy are excluded

Hodges JR, Warlow CP. Syndromes of transient amnesia: towards a classification. A study of 153 cases. J Neurol Neurosurg Psychiatry 1990;53:834-43. 
23.5 per 100,000 [3]. To date, there is no way to diagnose TGA through laboratory investigations [3]. Therefore, the diagnosis depends on detailed clinical records of objective witnesses, cognitive evaluation, and physical examination, and the specific diagnostic criteria are presented in Table 1 [3,6. Patients repeatedly ask questions, such as "Why are we here?", "What time is it?", and "How did I get here?" The answers are immediately forgotten owing to their inability to encode new information [3]. In this case, there was no change in consciousness or subjective responses except for anterograde amnesia as the patient repeatedly asked the same questions because of memory lapse. The patient did not remember how to get to the hospital, and was disoriented to time and place. The patient recovered memory after approximately one hour and showed no local neurological symptoms.

TGA episodes are sometimes preceded by trigger events, such as a Valsalva maneuver, emotional stress, immersion in cold or hot water, sexual intercourse, or pain [3,7]. The pathogenesis of TGA has been explained by three distinct hypothetical mechanisms: vascular (due to venous flow disturbances or focal arterial ischemia), epilepsy, and migraine [8-10]. In this case, the patient experienced hyperventilation due to severe pain during IMS, and vasoconstriction due to hypocapnia, resulting in transient hypoperfusion characterized by decreased cerebral blood flow.

The intracranial venous hypertension may have induced reactive arterial vasoconstriction to compensate for the increased cerebral blood volume, and the resulting relative hypoperfusion may trigger amnesia in susceptible individ- uals $[11,12]$. In this case, the patient adopted a prone position with a pillow under the abdomen for pain intervention that shifted the organs in the abdominal cavity toward the diaphragm, which may have increased the intrathoracic pressure. In addition, behaviors such as involuntary Valsalva maneuvers that occur during pain increase intrathoracic pressure. According to Lewis's hypothesis, if the intrathoracic pressure is excessive during Valsalva maneuver, the circulation of cerebral blood flow through the internal jugular vein is disturbed, resulting in venous ischemia in the areas that control memory, such as the temporal lobe, hippocampus, and midbrain $[2,4,13]$. This transient venous ischemia in the brain causes anterograde amnesia. In this case, the patient had no history of epilepsy, but had a history of taking medication for migraine. A large population-based study indicated that patients with migraine, particularly middle-aged women, are at a higher risk of TGA [14].

Unfortunately, there is no specific treatment for TGA [3]. Episodes are self-limited, and improvement is noted within 24 hours without any intervention. Additional tests may be required for differential diagnosis of diseases that require acute treatment or secondary prevention, such as transient epileptic amnesia (TEA) or transient ischemic attack (TIA) [15]. Table 2 shows the differential diagnosis of TGA [3].

In conclusion, in this case, TGA may have been caused by a combination of hyperventilation due to treatment-induced pain, intracranial hypoperfusion due to increased intrathoracic pressure, and a history of migraine. TGA is a syndrome with complete recovery of symptoms within a short period of time. However, reports of amnesia after

Table 2. Difference diagnosis of TGA

\begin{tabular}{|c|c|c|c|c|c|c|c|c|}
\hline Condition & Risk factors & $\begin{array}{l}\text { Precipitating } \\
\text { factors }\end{array}$ & Duration & $\begin{array}{l}\text { Associated neurologic } \\
\text { symptoms }\end{array}$ & MRI & EEG & $\begin{array}{l}\text { Recurrence } \\
\text { of attacks }\end{array}$ & $\begin{array}{c}\text { Response to } \\
\text { anticonvulsant } \\
\text { medications }\end{array}$ \\
\hline TGA & Migraine & Yes* & $4-6 h$ & No & $\begin{array}{l}\text { Hippocampal DWI } \\
\text { hyperintensity, without } \\
\text { permanent lesion }\end{array}$ & Normal & Low & No \\
\hline TEA & No & $\mathrm{No} / \mathrm{Yes}^{\dagger}$ & $<60 \min ^{\ddagger}$ & $\begin{array}{l}\text { No/yes (oral } \\
\text { automatisms, } \\
\text { olfactory or gustatory } \\
\text { hallucinations) }\end{array}$ & $\begin{array}{l}\text { Normal/hippocampal } \\
\text { sclerosis or atrophy }\end{array}$ & $\begin{array}{c}\text { Abnormal } \\
\text { (temporal or } \\
\text { frontotemporal } \\
\text { regions) }\end{array}$ & High & Yes \\
\hline $\mathrm{TIA} /$ stroke & $\begin{array}{l}\text { Vascular risk } \\
\text { factors }\end{array}$ & No & $\begin{array}{l}\text { Minutes to } \\
\text { permanent } \\
\text { impairment }\end{array}$ & No/yes (any) & $\begin{array}{l}\text { DWI with T2-FLAIR } \\
\text { permanent lesion }\end{array}$ & Normal & Low & No \\
\hline
\end{tabular}

TGA: transient global amnesia, MRI: magnetic resonance imaging, EEG: electroencephalography, DWI: diffusion-weighted imaging, TEA: transient epileptic amnesia, TIA: transient ischemic attack, FLAIR: fluid-attenuated inversion recovery.

*Valsalva maneuver, emotional stress, immersion in cold or hot water, sexual intercourse, or pain. ${ }^{\dagger}$ Waking. ${ }^{\dagger}$ Often a few minutes. 
pain interventions are rare, suggesting the need for vigilance without panic in the event of temporary and partial memory loss. In addition, it is necessary to rapidly examine the patient's history and risk factors for ischemic brain disease for differential diagnosis, followed by appropriate treatment. In this case, the authors recommended additional investigation, which the patient refused. Therefore, no differential diagnosis was made and no appropriate treatment was provided.

\section{CONFLICT OF INTEREST}

No potential conflict of interest relevant to this article was reported.

\section{REFERENCES}

1. Fisher CM, Adams RD. Transient global amnesia. Acta Neurol Scand Suppl 1964;40:1-83.

2. Lewis SL. Aetiology of transient global amnesia. Lancet 1998; 352:397-9.

3. Arena JE, Rabinstein AA. Transient global amnesia. Mayo Clin Proc 2015;90:264-72.

4. Sander K, Sander D. New insights into transient global amnesia: recent imaging and clinical findings. Lancet Neurol 2005;4:437-44.

5. Bortolon RJ, Weglinski MR, Sprung J. Transient global amnesia after general anesthesia. Anesth Analg 2005;101:916-9.

6. Hodges JR, Warlow CP. Syndromes of transient amnesia: towards a classification. A study of 153 cases. J Neurol Neuro- surg Psychiatry 1990;53:834-43.

7. Quinette P, Guillery-Girard B, Dayan J, de la Sayette V, Marquis S, Viader F, et al. What does transient global amnesia really mean? Review of the literature and thorough study of 142 cases. Brain 2006;129:1640-58.

8. Bartsch T, Deuschl G. Transient global amnesia: functional anatomy and clinical implications. Lancet Neurol 2010;9: 205-14.

9. Calabresi P, Centonze D, Pisani A, Cupini L, Bernardi G. Synaptic plasticity in the ischaemic brain. Lancet Neurol 2003;2: 622-9.

10. Kosuge Y, Imai T, Kawaguchi M, Kihara T, Ishige K, Ito Y. Subregion-specific vulnerability to endoplasmic reticulum stress-induced neurotoxicity in rat hippocampal neurons. Neurochem Int 2008;52:1204-11.

11. Caplan LR. Transient global amnesia and jugular vein incompetence. Stroke 2010;41:e568; author reply e569.

12. Di Filippo M, Calabresi P. Ischemic bilateral hippocampal dysfunction during transient global amnesia. Neurology 2007;69:493.

13. Nakada T, Kwee IL, Fujii Y, Knight RT. High-field, T2 reversed MRI of the hippocampus in transient global amnesia. Neurology 2005;64:1170-4.

14. Lin KH, Chen YT, Fuh JL, Li SY, Chen TJ, Tang CH, et al. Migraine is associated with a higher risk of transient global amnesia: a nationwide cohort study. Eur J Neurol 2014;21:71824.

15. Toledo M, Pujadas F, Purroy F, Lara N, Quintana M, Álvarez-Sabin J. [Recurrent transient global amnesia, a manifestation of ischemic cerebrovascular disease]. Med Clin (Barc) 2005;125:361-5. Spanish. 